\title{
KAJIAN TEORITIS TENTANG SPESIFIKASI ENGINE 1NR-VE
}

\author{
${ }^{(1)}$ Ali Syahbana, ${ }^{(2)}$ Gusti Rusydi Furqon Syahrillah \\ ${ }^{(1)(2)}$ Prodi Teknik Mesin Fakultas Teknik, Universitas Islam Kalimantan MAB \\ Jl. Adhiyaksa No. 2 Kayu Tangi, Banjarmasin \\ Email: alisyahbana288@gmail.com,rani_rusdi@yahoo.com
}

\begin{abstract}
ABSTRAK
Engine yang tenaga nya di gunakan pada mobil harus memiliki kinerja yang kompak, ringan dan dimamis dalam setiap aspek operasional. Mesin harus dapat menghasilkan kecepatan yang tinggi dan tenaga yang besar, mudah dioperasikan dan senyap, oleh karena itu mesin bensin sekarang selalu mengalami penyempurnaan untuk dapat di gunakan oleh setiap keperluan medan, salah satu di antaranya adalah type engie 1 NRVE Setelah melakukan dan melewati beberapa pengujian, maka dapat data dan di analisa. Untuk dapat memeriksa keadaan sebenarnya dari hasil penelitian ini di perlukan beberapa hal yang dapat membantu suatu analisa yaitu: Data spesifikasi engine, tabulasi, Perhitungan, Grafik, Analisa dan terakhir berupa kesimpulan yang dapat di ambil dari hasil pembahasan dan analisa data pengujian serta saran yang dapat di berikan dari hasil pengujian.Dari data hasil pengujian dan analisa yang telah dilakukan, maka dapat ditarik kesimpulan bahwa : Untuk putaran mesin $1000 \mathrm{rpm}$ akan didapat gaya $(F)=1.15 \mathrm{Nm}$ dengan daya $(P)=125,60$ ps. Sedangkan $T_{3}=635 \mathrm{~K}$ dan $\mathrm{T}_{4}$ $=252,8 \mathrm{~K}$. Pada mesin $2000 \mathrm{rpm}$ akan didapat gaya $(\mathrm{F})=0,57 \mathrm{Nm}$ dengan daya $(\mathrm{P})=$ 62,45 ps. Sedangkan $\mathrm{T}_{3}=662,13 \mathrm{~K}$ dan $\mathrm{T}_{4}=263,6 \mathrm{~K}$. kemudian untuk mesin 3000 rpm akan didapat gaya $(F)=0,38 \mathrm{Nm}$ dengan daya $(\mathrm{P})=41,63 \mathrm{ps}$, Sedangkan $\mathrm{T}_{3}=$ $885,44 \mathrm{~K}$ dan $\mathrm{T}_{4}=352,5 \mathrm{~K}$. Sedangkan pada hasil uji dan perhitungan Untuk effisiensi mesin didapat $\eta$ th $=0,602$ atau $60,2 \%$
\end{abstract}

Kata Kunci : mesin bensin, tenaga kuda dan Daya

\section{PENDAHULUAN}

Dunia Otomotif dijaman sekarang mengalami banyak sekali kemajuan bukan hanya pada jenis bodi, rangka dan mesin. Sehingga dalam waktu singkat sering terjadi perubaahan perubahan pada bodi, rangka dan type mesin dengan merk mobil dan jenis mobil yang sama. Dapat dilihat dalam beberapa tahun terakhir, banyak sekali model dan type mesin mengalami perubahan.

Mobil adalah salah satu angkutan transportasi yang paling banyak digunakan pada masa sekarang. Baik mobil pribadi ataupun mobil umum sudah menjadi minat utama dalam melakukan kegiatan ke seharian, karena mobil mempunyai keutamaan yang tidak dimiliki transportasi lain yang saat ini juga banyak digunakan seperti motor dan bus. Mobil dapat dinaiki beberapa orang sekaligus, di bandingkan dengan motor yang Cuma muat dinaiki 2 orang saja, sehingga membutuhkan banyak motor untuk berpergian bersama sanak keluarga atau teman - teman, Sedangkan bus bisa dinaiki oleh banyak orang namun karena mempunyai bentuk yang panjang dan besar, sehingga membuat bus tidak lebih efisien dibandingkan mobil.

Mesin yang di gunakan pada mobil,merupakan salah satu komponen yang sangat penting yaitu sebagai suatu 
komponen yang mengubah energi panas yang dihasilkan dari proses pembakaran kemudian diubah menjadi kerja melalui mekanisme dengan gerak translasi lurus bolak-balik dari torak menjadi gerak putar pada poros engkol. Mesin yang tenaga nya di gunakan pada suatu mobil harus kompak, ringan dan mudah di tempatkan pada ruangan terbatas. Mesin harus bisa menghasilkan kecepatan yang tinggi dan memiliki tenaga yang besar, mudah di operasikan dan tidak bising, oleh karena itu mesin bensin dan mesin Diesel umum nya banyak di gunakan pada unit kendaraan atau mobil.

Salah satu kemajuan teknologi engine atau mesin yang dapat kita lihat pada mobil merk Toyota Avanza dengan seri engine $\boldsymbol{l} \boldsymbol{N R}-\boldsymbol{V E}$ adalah seri terbaru dari engine/mesin produk Toyota Avanza ini, dengan 2 jenis isi silinder yaitu $1.496 \mathrm{cc}$ dan $1.329 \mathrm{cc}$. Dengan daya maksimum dihasilkan pada $1496 \mathrm{cc}=104$ ps dengan kecepatan putar $6000 \mathrm{rpm}$. Dan pada $1.329 \mathrm{cc}=96,5$ ps dengan kecepatan putaran $6000 \mathrm{rpm}$. Serta menghasilakan Torsi Maksimum pada $1.496 \mathrm{cc}=13,9$ kgm pada kecepatan putar $4.200 \mathrm{rpm}$ dan pada $1.329 \mathrm{cc}=12,3 \mathrm{kgm}$ pada kecepatan putaran $4.200 \mathrm{rpm}$.

\section{METODE PENELITIAN}

- Tempat penelitian

Penelitian ini bertempat di Wira Toyota Banjarmasin, jalan Jend. A. Yani km 10, Kertak Hanyar, Kabupaten Banjar.

\section{- Waktu penelitian}

Waktu penelitian di laksanakan sejak bulan Mei sampai dengan Juli 2018.

- Alat dan Bahan

1.GTS(Global Tech Stream)
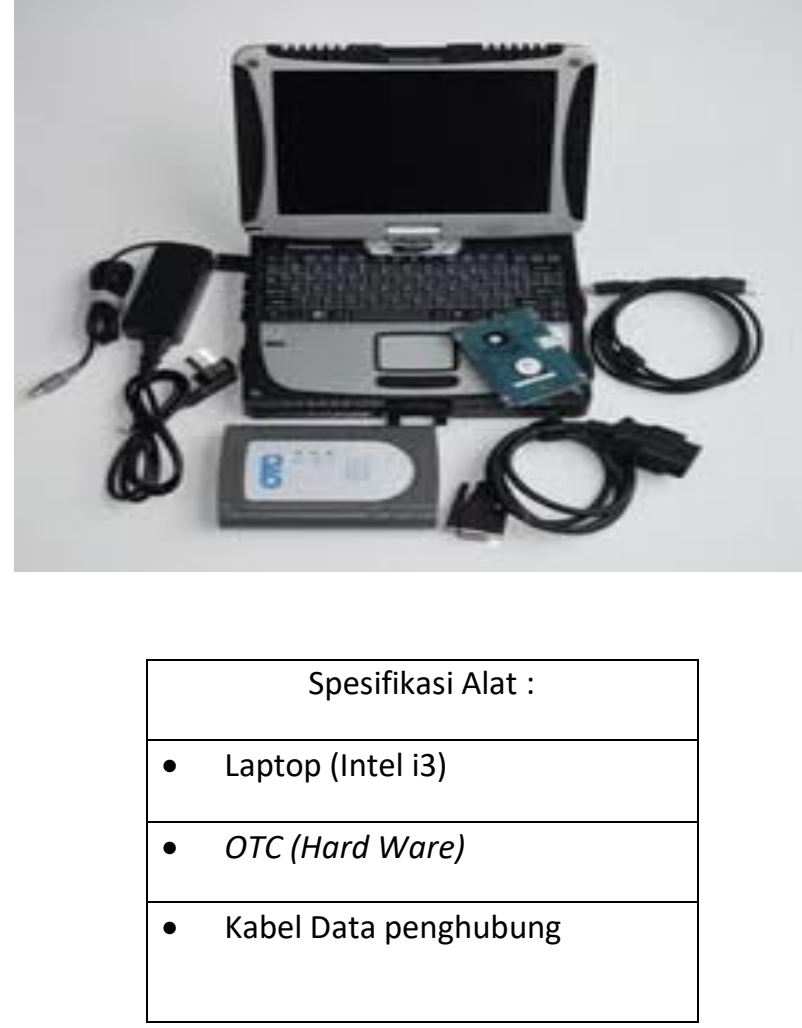

2.Petrol Engine Compression Tester Kit

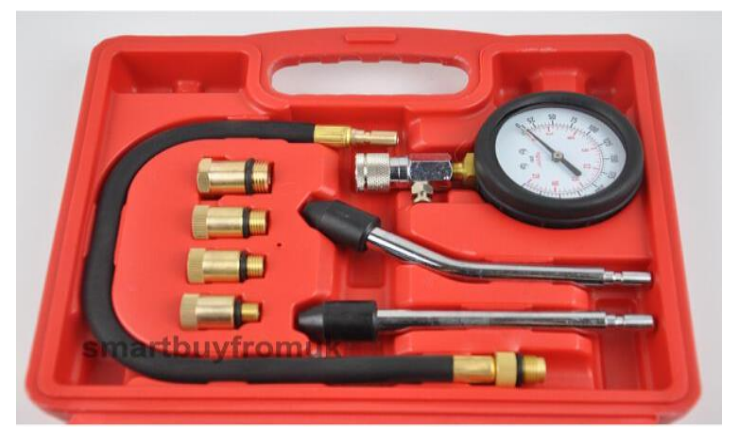

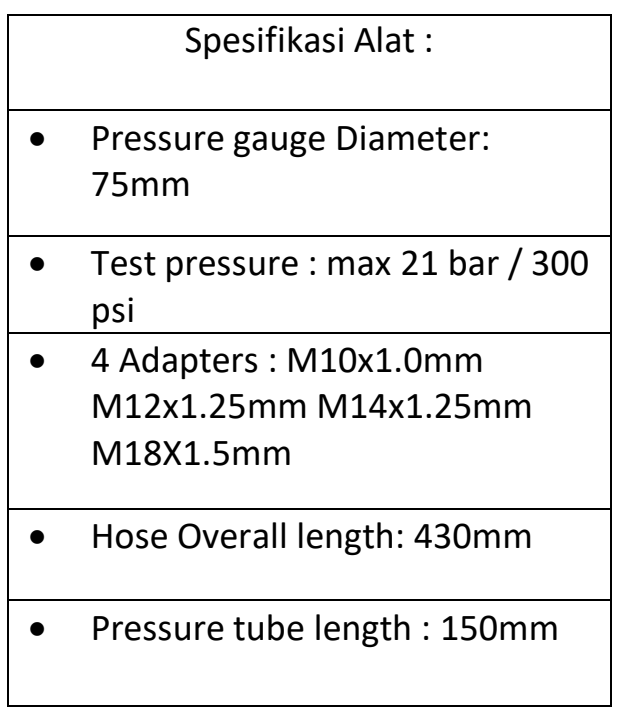



- Angled pressure tube length :
$160 \mathrm{~mm}$

- $\quad$ Case Size : 265 × $210 \times 65 \mathrm{~mm}$

- Teknik Pengambilan Data

Adapun Teknik pengambilan data adalah sebagai berikut:

1. Alat ukur dan Mesin sudah di set sesuai prosedur yang di sarankan

2. Ukur dan catat hasil dari pembacaan alat yang di hasilkan.

3. Setelah selesai rapikan kembali alat dan mesin dan kembalikan ketempat semula.

Teknik pengumpulan data pada saat pengujian, sebagai berikut:

1. Data diambil harus sudah sesuai dengan prosedur yang di sarankan

2. Hasil dari pembacaan alat masukan kedalam tabel yang sudah disiapkan..

\section{Teknik Pengolahan Data}

Setelah melakukan dan melewati beberapa pengujian, maka penguji dapat melakukan pengolahan data dan dapat menganalisa.

1. Analisa

Untuk dapat memeriksa keadaan sebenarnya dari hasil penelitian ini di perlukan beberapa hal yang dapat membantu suatu analisa yaitu:
a. Data Spesifikasi
b. Tabel
c. Perhitungan
d. Grafik
e. Analisa.

2. Kesimpulan

Berisikan kesimpulan yang dapat di ambil dari hasil pembahasan dan analisa data pengujian serta saran yang dapat di berikan dari hasil pengujian.

\section{HASIL DAN PEMBAHASAN}

\section{Analisa Data}

Spesifikasi engine yang diambil adalah adalah 1NR-VE dengan datadata sebagai berikut:

Tabel. 4.1 Spesifikasi Engine

\begin{tabular}{|c|c|}
\hline \multirow{2}{*}{ Varian } & Veloz 1,3 \\
\hline & $\mathrm{M} / \mathrm{T}$ \\
\hline Mesin & 1NR-VE, 4 Silinder, DOHC, 16 Valve, Dual VVT-i \\
\hline Kapasitas (cc) & 1.329 \\
\hline Tenaga Maks (ps/rpm) & $96.5 / 6.000$ \\
\hline Torsi Maks (Nm/rpm) & $120 / 4.200$ \\
\hline Transmisi & Otomatis 4 speed \\
\hline Ratio Compresi & $11: 1$ \\
\hline
\end{tabular}

Dari data diatas maka diambil salah satu contoh perhitungan pada engine mobil disesuaikan dengan sfesifikasi yang ada maka:

a. Gaya ( F )

$\mathrm{T}=\mathrm{F} \times \mathrm{r}$

Dimana dalam satuan SI:

$\mathrm{T}=$ torsi $(\mathrm{Nm})$

$\mathrm{F}=$ gaya penyeimbangan $(\mathrm{N}$ atau kgmm)

$\mathrm{r}=$ jarak lengan torsi $(\mathrm{m})=$

Untuk menghitung Gaya (F)

pada $1000 \mathrm{rpm}$

$\mathrm{F}=\mathrm{T} / \mathrm{r}$

Dimana : $r=(2 \pi \cdot n) / 60$ $\mathrm{r}=$ putaran Mesin sehingga $\mathrm{r}=(2.3,14.1000) / 60=104,67 \mathrm{rpm}$

Sehingga gaya pada mesin :

$\mathrm{F}=\mathrm{T} / \mathrm{r}=120 / 104.67=1.15 \mathrm{~kg} \cdot \mathrm{mm}$

Untuk menghitung Gaya (F)

pada $2000 \mathrm{rpm}$

$\mathrm{F}=\mathrm{T} / \mathrm{r}$

Dimana : $r=(2 \pi . n) / 60$ $\mathrm{r}=$ putaran Mesin sehingga $\mathrm{r}=(2.3,14.2000) / 60=209,33 \mathrm{rpm}$

Sehingga gaya pada mesin :

$\mathrm{F}=\mathrm{T} / \mathrm{r}=120 / 209,33=0.57 \mathrm{~kg} \cdot \mathrm{mm}$

Untuk menghitung Gaya (F) pada $3000 \mathrm{rpm}$

$\mathrm{F}=\mathrm{T} / \mathrm{r}$

Dimana : $r=(2 \pi . n) / 60$

$\mathrm{r}=$ putaran Mesin sehingga

$\mathrm{r}=(2.3,14.3000) / 60=314 \mathrm{rpm}$

Sehingga gaya pada mesin : 
$\mathrm{F}=\mathrm{T} / \mathrm{r}=120 / 314=0.38 \mathrm{~kg} \cdot \mathrm{mm}$ Daya ( P )

$\mathrm{P}=\mathrm{F} \mathrm{x} \mathrm{V}$

dimana dalam satuan SI:

$\mathrm{P}=$ daya $(\mathrm{kW})$

$\mathrm{F}=$ Gaya $(\mathrm{Nm})$

$\mathrm{v}=\operatorname{Kecepatan}(\mathrm{cm} / \mathrm{s})$

Sedangakan untuk rumus

$\mathrm{v}=2 . \pi \cdot \mathrm{r} . \mathrm{n} / 120$

Sehingga :

$$
\begin{aligned}
\mathrm{v} & =(2.3,14.104,67.1000) / 60 \\
& =10.955,46 \mathrm{~cm} / \mathrm{s}
\end{aligned}
$$

Kemudian akan didapat daya

pada $\mathrm{F}=1,15 \mathrm{Nm}$

$\mathrm{P}=1.15 \times 10.955,46$

$$
=12.560 \mathrm{~kW}=125,6 \mathrm{ps}
$$

Kemudian akan didapat daya pada $\mathrm{F}=0,57 \mathrm{Nm}$

$$
\begin{aligned}
\mathrm{P} & =0.57 \times 10.955,46 \\
& =6.244,61 \mathrm{~kW}=62,45 \mathrm{ps}
\end{aligned}
$$

Kemudian akan didapat daya pada $\mathrm{F}=0,38 \mathrm{Nm}$

$$
\begin{aligned}
\mathrm{P} & =0.38 \times 10.955,46 \\
& =4.163,08 \mathrm{~kW}=41,63 \mathrm{ps}
\end{aligned}
$$

Effisiensi thermal ( $\eta$ th )

$\eta$ th $=1-(\mathrm{Q}$ out $) /(\mathrm{Q}$ in $)$

Diketahui Suhu udara $\mathrm{T} 1=300 \mathrm{C}=$ 3030K

Sedangkan Untuk Rasio Kompresi $(\gamma \mathrm{c})$ $=10$

Untuk Volume Langkah Vd $=1.329 \mathrm{cc}$ $=0,001329 \mathrm{~mm} 3$

Maka : volume sisa

$$
\begin{gathered}
\gamma \mathrm{c}=(\mathrm{Vc}+\mathrm{Vd}) /(\mathrm{Vc}) \\
10=(\mathrm{Vc}+0,001329) /(\mathrm{Vc}) \\
\gamma \mathrm{c}=0,0001329 \mathrm{~mm} 3
\end{gathered}
$$

Kemudian

$$
\begin{aligned}
\mathrm{T}_{2} & =\mathrm{T}_{1} \cdot(\gamma \mathrm{c})^{\mathrm{k}-1} \\
& =303 \mathrm{~K} \cdot 10^{0,4} \\
& =761,1 \mathrm{~K}
\end{aligned}
$$

Sedangkan $\mathrm{T}_{3}$

$\mathrm{T}_{3}=\left(\mathrm{T}_{2} \times \mathrm{T}_{4}\right) /\left(\mathrm{T}_{1}\right)$

Sehingga $\mathrm{T}_{3}$ pada $1000 \mathrm{rpm}$

$\mathrm{T}_{3}=(761,1 \times 525,8) /(303)$

$=1.320,75 \mathrm{~K}$

Sehingga T3 pada $2000 \mathrm{rpm}$

$\mathrm{T}_{3}=(761,1 \times 536,6) /(303)$

$$
=1.347,88 \mathrm{~K}
$$

\begin{tabular}{|c|c|c|c|c|c|c|c|c|}
\hline \multicolumn{9}{|c|}{$\mathrm{bu} \mathrm{G}_{3 \mathrm{~s}}$} \\
\hline No & $\begin{array}{l}\text { Ruang } \\
\text { Baksar } \\
\text { (V) }\end{array}$ & $\begin{array}{c}\text { Torsi } \\
\text { (T) }\end{array}$ & $\begin{array}{c}\text { Putran } \\
\text { (Rpm) }\end{array}$ & $\begin{array}{c}\text { Linghungan } \\
\text { (TI) }\end{array}$ & $\begin{array}{l}\text { Buang } \\
\text { (T4) }\end{array}$ & $\begin{array}{l}\text { Gava } \\
\text { (F) }\end{array}$ & $\begin{array}{l}\text { Dava } \\
\text { (P) }\end{array}$ & $\begin{array}{c}\text { Eff } \\
(\eta t h)\end{array}$ \\
\hline 1 & $1.329 \approx c$ & 120 & 1000 & $30^{\circ} \mathrm{C}$ & $252,8^{\circ} \mathrm{C}$ & 1.15 & 125,60 & 0,602 \\
\hline 2 & $1.329 \propto c$ & 120 & 2000 & $30^{\circ} \mathrm{C}$ & $263,6 \mathrm{C}$ & 0.57 & 62,45 & 0,002 \\
\hline 3 & $1.329 \propto c$ & 120 & 3000 & $30 \mathrm{C}$ & $352,5 \mathrm{C}$ & 0.38 & 41,65 & 0,002 \\
\hline
\end{tabular}

Sehingga T3 pada $3000 \mathrm{rpm}$

$\mathrm{T}_{3}=(761,1 \times 625,5) /(303)$

$$
=1.520,94 \mathrm{~K}
$$

Sedangkan untuk Effisisensi :

$\eta$ th $=1$ - (Q out $) /(Q$ in $)$

Untuk effisiensi mesin otto bisa dgunakan persamaan :

$\eta$ th $=1-(\mathrm{Q}$ out $) /(\mathrm{Q}$ in $)=1-\mathrm{T} 1 / \mathrm{T} 2$

Maka

$\eta$ th $=1-\mathrm{T} 1 / \mathrm{T} 2$

$\eta$ th $=1-303 / 761,1$

$$
=0,602
$$

\section{Hasil}

Untuk aspek ekonomis dapat diambil dari data yang dikeluarkan pihak Toyota dimana menyematkan knock sensor baru pada mobil itu. Knock sensor ini memungkinkan penggunaan bahan bakar yang lebih bervariasi, di mana RON 92 merupakan baan bakar ideal untuk mobil ini. Pada inti nya, Grand New Avanza lebih cocok untuk menggunakan bahan bakar setara Pertamax.

Kompresi mesin 10 memiliki batas penggunaan bahan bakar di bawah RON 92 dan di atas RON 90. "Minimal di angka itu biar bisa dapat tenaga dan torsi maksimal. mobil hanya bisa dihidupkan dengan kunci yang sudah terdaftar di komputer mobil. Sehingga keamanan mobil akan lebih terjaga.

\section{KESIMPULAN}

Dari data hasil pengujian dan analisa yang telah di lakukan, maka dapat ditarik kesimpulan bahwa :

1. Untuk putaran mesin $1000 \mathrm{rpm}$ akan didapat gaya $(F)=1.15 \mathrm{Nm}$ dengan daya $(\mathrm{P})=125,60$ ps. Sedangkan $\mathrm{T} 3=635 \mathrm{~K}$ dan $\mathrm{T}_{4}=$ 
252,8 C. Pada mesin $2000 \mathrm{rpm}$ akan didapat gaya $(\mathrm{F})=0,57 \mathrm{Nm}$ dengan daya $(\mathrm{P})=62,45$ ps. Sedangkan $\mathrm{T} 3=662,13 \mathrm{~K}$ dan $\mathrm{T}_{4}$ = 263,6 C. kemudian untuk mesin $3000 \mathrm{rpm}$ akan didapat gaya $(\mathrm{F})=$ $0,38 \mathrm{Nm}$ dengan daya $(\mathrm{P})=41,63$ ps, Sedangkan $\mathrm{T} 3=885,44 \mathrm{~K}$ dan $\mathrm{T}_{4}=352,5 \mathrm{C}$.

2. Sedangkan pada hasil uji dan perhitungan Untuk effisiensi mesin didapat $\eta t h=0,602$ atau $60,2 \%$

\section{REFERENSI}

[1] Aris Munandar, Wiranto, 1988. Penggerak mula motor bakar torak. Institut Technologi Bandung

[2] Daryanto, Drs. 2009. Tekniik Otomotif. Bumi Aksara. Jakarta.

[3] https://auto2000.co.id/6-keunggulanmesin-baru-avanza-veloz/

[4] https://webcache.googleusercontent.c om/search?q=cache:3GWmp6rDAz0 J:https://media.neliti.com/media/publ ications/194282-ID-uji-unjuk-kerjadan-durability-5000-km-

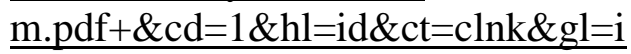
$\underline{\mathrm{d}}$

[5] https://media.neliti.com/media/public ations/176987-ID-analisa-sistembahan-bakar-injeksi-pada.pdf

[6] https://media.neliti.com/.../149044ID-peningkatan-kinerja-toyotaavanza-15-den.pdf

[7] http://repository.usu.ac.id/bitstream/h andle/123456789/12016/09E01628.p df/?sequence $=1$

[8] https://www.google.co.id/url?sa=t\&r $\mathrm{ct}=\mathrm{j} \& \mathrm{q}=\&$ esrc $=\mathrm{s} \&$ source $=$ web $\& \mathrm{~cd}=$ $\underline{10 \& \mathrm{cad}=\mathrm{rja} \& u a c t=8 \& \mathrm{ved}=0 \text { ahUKE }}$ wjpvmU15HbAhWKp48KHZIUDAEQ FgiCATAJ\&url=http\%3A\%2F\%2Fe repo.unud.ac.id\%2F15138\%2F3\%2F 0404305062-3-

BAB_II.pdf\&usg=AOvVaw1DVokY mcexzRaUu1q5Orfm
[9] https://www.google.co.id/search?q=sikl us+otto+termodinamika+pdf\&ei $=\mathrm{mMj}$ Wv76M4rPvgSSqbAI\&start $=10 \& s a=N$ \&biw $=1366 \&$ bih $=626$ 